\title{
Properties of Crushed Red-Bed Soft Rock Mixtures Used in Subgrade
}

\author{
Huayan Yao, ${ }^{1,2}$ Shanpo Jia, ${ }^{3}$ Wenning Gan, ${ }^{1,2}$ Zhenhua Zhang, ${ }^{1,2}$ and Kunlin Lu ${ }^{1,2}$ \\ ${ }^{1}$ School of Civil and Hydraulic Engineering, Hefei University of Technology, Hefei, Anhui 230009, China \\ ${ }^{2}$ Anhui Key Laboratory of Civil Engineering and Materials, Hefei, Anhui 230009, China \\ ${ }^{3}$ School of Urban Construction, Yangtze University, Jingzhou 434023, China \\ Correspondence should be addressed to Shanpo Jia; jiashanporsm@163.com
}

Received 4 January 2016; Accepted 6 December 2016

Academic Editor: Carlo Santulli

Copyright (C) 2016 Huayan Yao et al. This is an open access article distributed under the Creative Commons Attribution License, which permits unrestricted use, distribution, and reproduction in any medium, provided the original work is properly cited.

\begin{abstract}
Slaking red-bed soft rocks are widely distributed in the south of Anhui Province, China, and several highways will go through this area. It is important to evaluate their physical and mechanical characteristics for the purpose of using this kind of soft rocks as materials for road construction. In this paper, the compacting tests, the resilient modulus tests, the California bearing ratio (CBR) tests, and permeability tests have been carried out on crushed red-bed soft rock mixtures. The test results showed that, for a given degree of compaction, the resilient modulus decreases linearly with the increase of moisture content. For a given moisture content, the resilient modulus and CBR values increase linearly with the increase of compaction degree, while the soaking swelling, water absorption capacity, and permeability coefficient decrease linearly. In other words, the strength and water stability are enhanced with the increase of the degree of compaction. The results demonstrate that the crushed red-bed soft rock mixtures can be directly used as materials for the highway construction by taking corresponding measures.
\end{abstract}

\section{Introduction}

Soft rock is one of the rock types encountered frequently in geotechnical engineering, which is less than the uniaxial compressive strength of $25 \mathrm{MPa}$, covering a series of sedimentary rocks, such as sandstone, mudstone, argillaceous sandstone, sandy mudstone, and siltstone. Generally, soft rocks are prone to slaking, swelling, collapse, breaking, softening, and argillization in the presence of humidity [1-6]. Such phenomenon can be quite crucial for various geotechnical hazards in roads, slopes, tunnels, and other engineering projects [7-10]. For example, when these soft rocks are used to fill subgrade, it is difficult to ensure the quality of the construction, often leading to excessive settlement, failure of embankments, and slope collapse.

Therefore, soft rocks are considered to be of very poor quality used for subgrade filling materials. In general, the soft rocks should be replaced with soil with better mechanical properties for subgrade filling, but this process will cause additional project costs and possibly extend the construction duration. Moreover, a large number of such rocks removed as excavated earth have an adverse effect on surrounding environment. Therefore, if soft rocks can be used for subgrade filling, not only can it save a great deal of investment and earthwork, but also substantial economic and environmental benefits can be achieved.

Some studies have focused on the physical and mechanical properties of the crushed soft rocks used as filling materials. The authors of [11] have conducted a staged compressionimmersion-direct shear test on the compacted samples of crushed mudstone aggregates, and the compressive and shear behaviors were discussed with attention to cementation effects. The authors of [12] have studied water-induced granular decomposition and its effects on geotechnical properties of crushed soft rocks. The authors of [13] have carried out cyclic loading tests on sandstone and limestone shale aggregates used in unbound forest roads.

Some researchers have paid attention to the techniques to make use of soft rocks as subgrade filling. The authors of [14] 
carried out research on the physical and mechanical properties of soft rocks after slaking, and research results show that the indexes of those slaked materials with compacting factor 95\% can reach the requirement of embankment. And the subgrade construction technology with the core of "preslaking/raking pressure/rolling pressure," construction quality control methods and detection measures were adopted in order to ensure the feasibility of using red sandstone as a subgrade filling.

In China, residential land development and transportation networks have been extended to mountainous areas due to rapid economic and population growth. Accordingly, road constructions have been carried out in many soft rock regions. In these regions, many sedimentary soft rocks, such as sandstone or mudstone, are distributed widely. Huangshan city, which exists in the southern mountains of Anhui Province, China, is one of the typical areas covered with many slaking soft rocks. The rocks in this area are red, dark red, or brown resulting from being rich in iron oxides. Some scholars have called them "red-bed soft rocks" $[15,16]$. Some construction measures, such as preslaking or adding lime, have been adopted to make full use of the red-bed soft rock as subgrade fillings [14, 17]. But those measures potentially extend the construction duration and increase the costs of the road projects. If the crushed red-bed soft rock in these areas can be directly used as subgrade fillings, the construction duration and investments of the road projects can be reduced.

Accordingly, the purpose of this study is to assess the applicability of crushed red-bed soft rock mixtures to road construction. In particular, the resilient modulus tests, the California bearing ratio (CBR) tests, and permeability tests were carried out on crushed soft rock mixtures with variable moisture contents or compaction degrees.

\section{Experimental Materials and Experimental Schemes}

2.1. Experimental Material. Naturally weathered red-bed soft rocks were obtained from a typical area of the quarry for the Jixi-Huangshan highway, in southern Anhui Province, China, as shown in Figure 1. These soft rocks include argillaceous feldspar quartz fine sandstone, calcareous argillaceous siltstone, argillaceous siltstone, iron-stain argillaceous calcareous siltstone, iron-stain argillaceous calcareous feldspar lithic sandstone, and mudstone.

In natural conditions, uniaxial compressive strength of the red-bed soft rocks generally ranges from 1.24 to $12.32 \mathrm{MPa}$, and the strength reduces sharply after they are soaked. Large blocks of rock samples were crushed resulting in coarse-grained soils in laboratory.

Due to the differences in their geological locations, the red-bed soft rock's chemical composition and physical characteristics are different even with the same weathering degree, which directly affect the mechanical properties. The structures of the samples mainly consist of silty-fine structure, silty structure, cryptocrystalline structure, argillaceous structure, pebbly silty-calcareous-argillaceous structure, and argillaceous structure (see Figure 2). The cemented form between the grains is dominated by a basal type cementation.

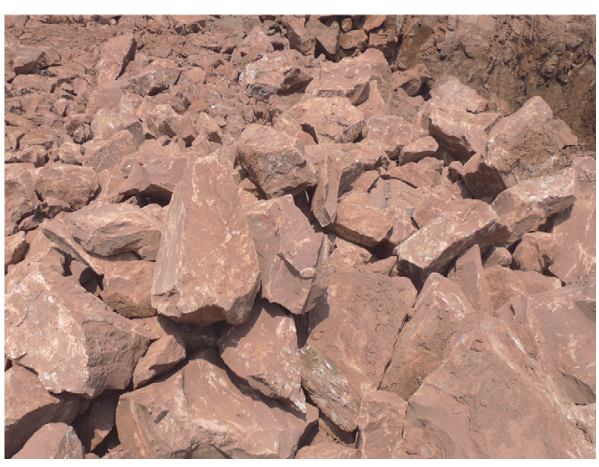

FIGURE 1: Representative red-bed sandstone sample.

The cementation matters are mainly argillaceous and calcareous, with low strength. The main mineral compositions of the soft rock samples used in this study are summarized in Table 1 .

2.2. Experimental Scheme. In the light of the construction duration, it is accepted in the construction process that soft rocks are crushed directly by machine instead of preslaking. For simulating the mechanical crushing process, the soft rock samples were artificially broken with a maximum diameter less than $20 \mathrm{~mm}$ (see Figure 3). Then, a series of mechanical tests were carried out according to Test Methods of Soil for Highway Engineering [18].

Firstly, the modified Proctor test compaction was used for the compaction in order to obtain the maximum dry density and optimum moisture content. Then, the resilient modulus test, California Bearing Ratio (CBR) test, and permeability test were carried out with different moisture contents or compaction degrees.

\section{Experimental Result}

3.1. Compaction Properties. The Proctor compaction test can determine the optimal moisture content (OWC) at which a given soil type becomes the most dense and achieves its maximum dry density. After the obtained rock samples underwent artificial mechanical crushing into small pieces, the aggregates were compacted in the steel mold with an inner diameter of $152 \mathrm{~mm}$ and height of $120 \mathrm{~mm}$. The compaction was performed in the way that the aggregates were placed into the mold in three layers; in each layer compaction was conducted using a $4.5 \mathrm{~kg}$ rammer, and the compaction energies were $2677.2 \mathrm{~kJ} / \mathrm{m}^{3}$.

The relation curve between dry density $\rho_{d}$ and moisture content $w$ is shown in Figure 4. The maximum dry density is $2.107 \mathrm{~g} / \mathrm{cm}^{3}$, and the optimum moisture content, $O W C$, is $8.8 \%$. Assessment of aggregates compaction is measured by the degree of compaction $(K)$, which is defined as the ratio of the current dry density and maximum dry density.

The coarse aggregates of the red-bed soft rocks will become smaller or transform into fine-grained soil during the rolling process. In this study, in order to investigate the moisture content and compaction effect on grains, particle 
TABLE 1: Main mineral composition.

\begin{tabular}{|c|c|c|c|c|c|c|c|c|c|}
\hline \multirow[b]{2}{*}{$\begin{array}{l}\text { Rock } \\
\text { sample } \\
\text { number }\end{array}$} & \multicolumn{9}{|c|}{ Main compositions (\%) } \\
\hline & Quartz & Feldspar & Debris & Dolomite & $\begin{array}{l}\text { Opaque } \\
\text { mineral }\end{array}$ & $\begin{array}{c}\text { Micrite } \\
\text { gravel }\end{array}$ & Calcite & $\begin{array}{l}\text { Iron-stain } \\
\text { clay mineral } \\
+ \text { sericite }\end{array}$ & Calcareous \\
\hline $1 \#$ & 35 & 20 & 5 & $<1$ & $<1$ & - & 3 & 30 & 7 \\
\hline $2 \#$ & 30 & 15 & 8 & - & $<1$ & 3 & 10 & 33 & - \\
\hline $3 \#$ & 3 & - & - & - & - & - & - & 97 & - \\
\hline $4 \#$ & 40 & 15 & 5 & $<1$ & $<1$ & - & 8 & 31 & - \\
\hline $5 \#$ & 40 & 10 & 5 & 1 & 1 & - & - & 30 & 13 \\
\hline $6 \#$ & 38 & 12 & 5 & 1 & $<1$ & - & - & 30 & 13 \\
\hline 7\# & 50 & 10 & & 5 & & - & 20 & 15 & - \\
\hline $8 \#$ & 55 & 10 & 1 & 1 & 3 & - & 15 & 15 & - \\
\hline 9\# & 4 & - & - & - & - & - & 40 & 56 & - \\
\hline $10 \#$ & 50 & 10 & - & 1 & 3 & 1 & 20 & 15 & - \\
\hline $11 \#$ & 38 & 8 & 19 & 3 & - & - & 20 & 10 & - \\
\hline $12 \#$ & 40 & 12 & 23 & $<1$ & - & - & 15 & 10 & - \\
\hline
\end{tabular}

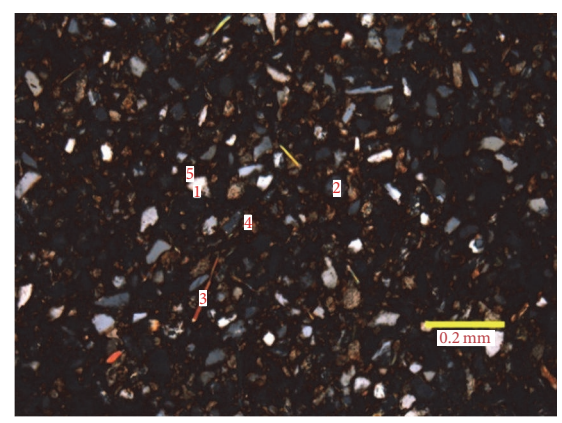

(a) Fine-silty structure

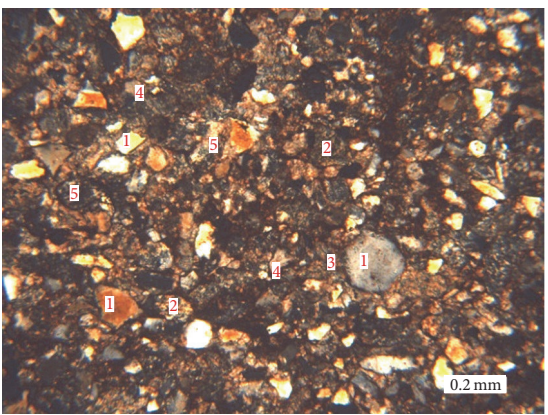

(d) Argillaceous fine structure

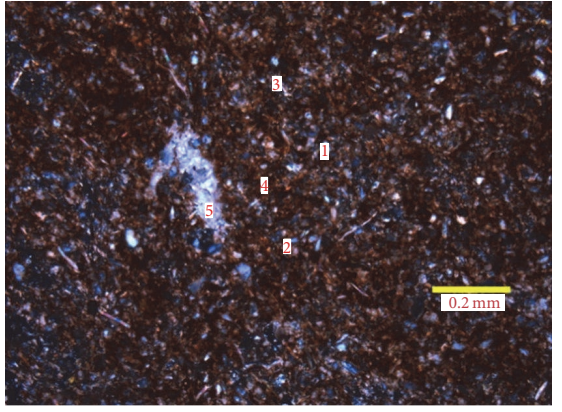

(b) Silty structure

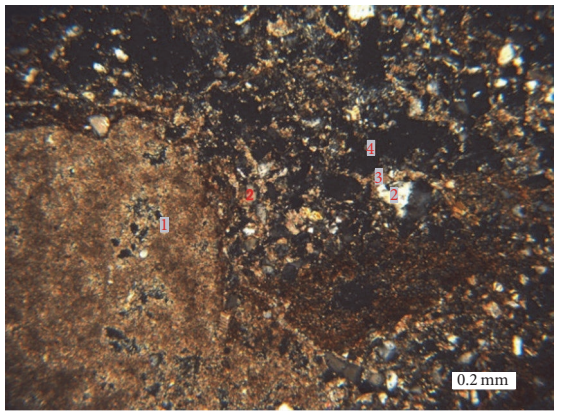

(e) Pebbly silty-calcareous-argillaceous structure

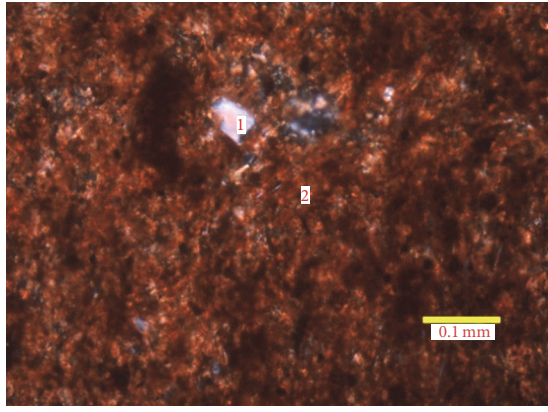

(c) Cryptocrystalline structure

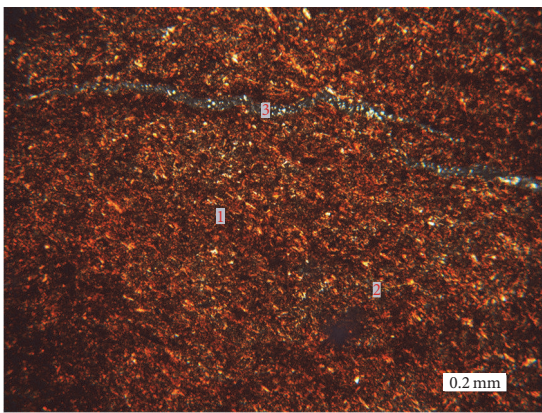

(f) Argillaceous structure

Figure 2: Microscopic structure diagram of representative red-bed soft rock.

size distribution tests were performed for the dry crushed soft rock mixtures and three compacted specimens with the moisture content of 5\%, $8 \%$, and $9 \%$ respectively, as shown in Figure 5. And the uniformity coefficient $C_{u}$ and gradation coefficient $C_{c}$ of each curve were calculated, as shown in Table 2.

The uniformity coefficient $C_{u}$ is defined as

$$
C_{u}=\frac{D_{60}}{D_{10}} .
$$

The gradation coefficient $C_{c}$ is defined as

$$
C_{c}=\frac{\left(D_{30}\right)^{2}}{D_{60} \cdot D_{10}},
$$

where $D_{60}, D_{30}$, and $D_{10}$ are diameter through which $60 \%$, $30 \%$, and $10 \%$ of the total soil mass are passing, respectively.

It can be seen from Table 2 that the coarse-grained soil has the uniformity coefficient $C_{u}$ greater than 5 , and the gradation coefficient $C_{c}$ is in the range 1-3 after compaction, 


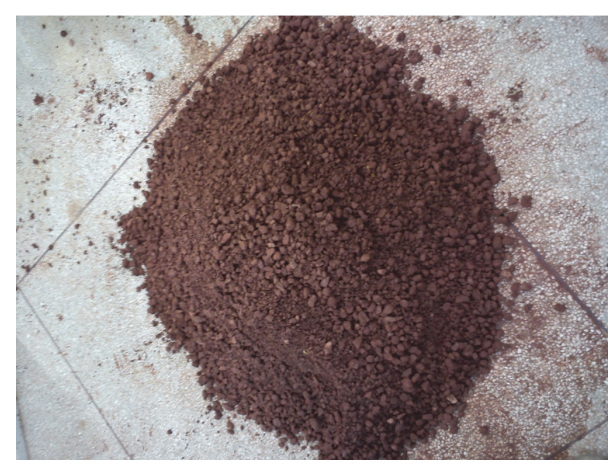

FIgURE 3: The crushed red-bed soft rock mixtures.

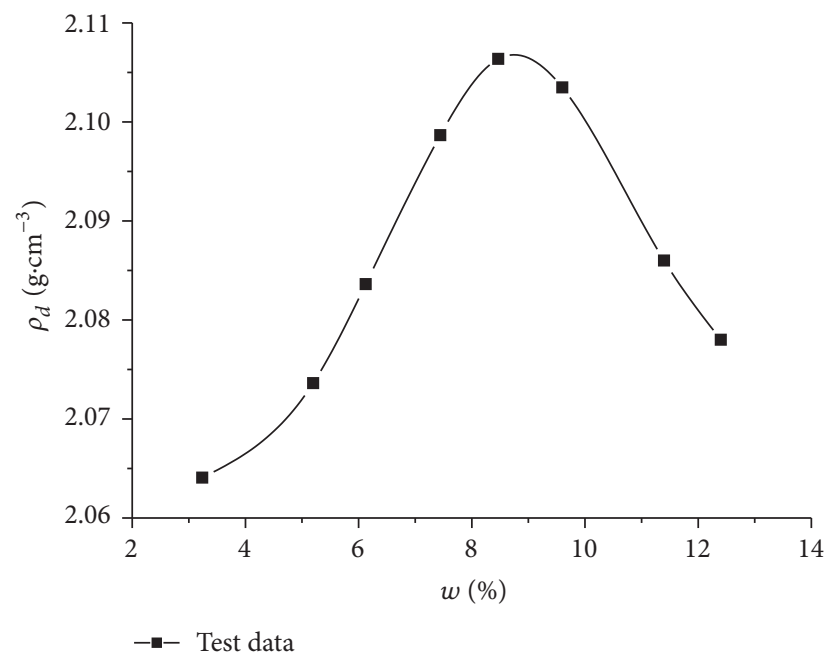

FIGURE 4: Relation between dry density $\rho_{d}$ and moisture content $w$.

TABLE 2: Uniformity coefficient $C_{u}$ and gradation coefficient $C_{c}$.

\begin{tabular}{lccccc}
\hline Test group & $D_{60}$ & $D_{30}$ & $D_{10}$ & $C_{u}$ & $C_{c}$ \\
\hline Before compaction & 9.4 & 5.3 & 1.2 & 7.83 & 2.49 \\
$w=9 \%$ & 4.8 & 1.8 & 0.23 & 20.87 & 2.93 \\
$w=8 \%$ & 4.1 & 1.3 & 0.16 & 25.63 & 2.58 \\
$w=5 \%$ & 3 & 0.55 & 0.09 & 33.33 & 1.12 \\
\hline
\end{tabular}

which shows the aggregates have a good size distribution. It is worthwhile to note that the uniformity coefficients of compacted crushed rock mixtures have become greater than that without compaction. In other words, the compaction and other construction technologies executed on broken soft rock mixtures can improve the particle grading, which leads to good engineering properties, such as smaller porosity, higher density, and large bearing capacity.

3.2. Test on Resilient Modulus. Resilient modulus $E_{r}$ is one of the mechanical parameters used to characterize subgrade soil strength, which is a vital parameter for pavement design. The most commonly applied resilient modulus models are the so-called universal models that relate the modulus to the deviatoric stress, confining pressure, or a combination

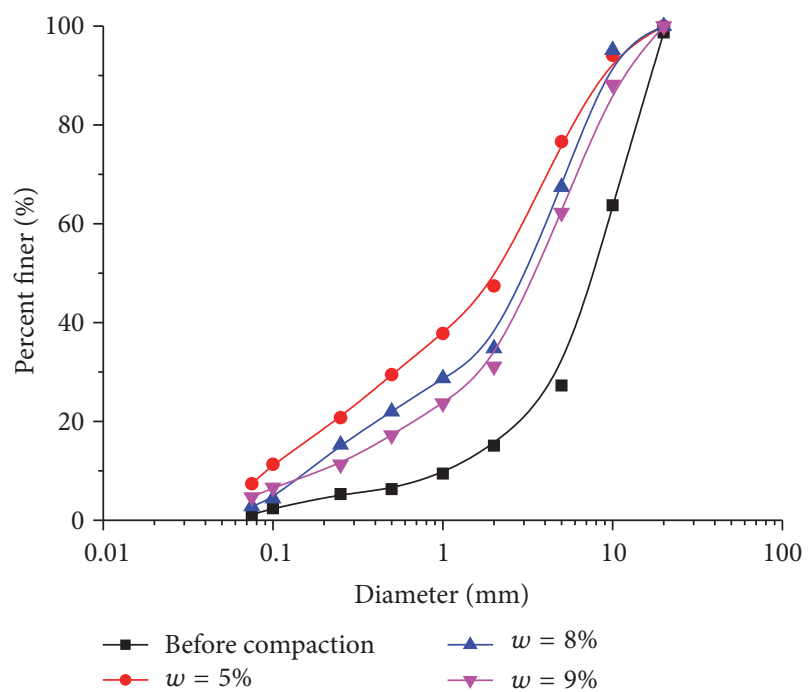

FIGURE 5: Particle size grading of crushed red-bed soft rock mixtures before and after compaction.

of them [19]. In this paper, the resilient modulus model in China's specification [18] is adopted and the modulus of the soil can be obtained by the Plate Load tests. The relationships between the resilient modulus and moisture content, as well as the compaction degree, are discussed.

Moisture is one of the main factors affecting the subgrade resilient modulus. The specimens with a compaction degree of $96 \%$ and moisture contents of $4.8 \%, 7.0 \%, 8.3 \%, 7.0 \%$, and $12.4 \%$ were prepared for the tests on resilient modulus. The results are shown in Figure 6.

Figure 6 reflects the influences of moisture content $(w)$ on the resilient modulus $\left(E_{r}\right)$. It can be seen that the resilient modulus has close relation with moisture content, decreasing with the increase of moisture content, and the general decline trend is approximately linear; around the optimum moisture content $\omega=8.8 \%$, the resilient modulus is not less than $90 \mathrm{MPa}$, which meets the requirement of national standard [20], in which the resilient modulus larger than $40 \mathrm{MPa}$ is demanded. However, the resilient modulus is $13.69 \mathrm{MPa}$ in the case of moisture content of $12.4 \%$. Therefore, the moisture content should be controlled close to the optimum moisture content. Based on the test results, the moisture content in the construction period is suggested to be no more than $11 \%$, so as to fulfill the strength performance of the subgrade filling required.

With the same moisture content of $9.0 \%$, the specimens with a compaction degree of $99.7 \%, 97.1 \%$, and $95.0 \%$ were prepared for the tests on the resilient modulus. Figure 7 illustrates the relation between the resilient modulus $\left(E_{r}\right)$ and the degree of compaction $(K)$. It can be seen that the resilient modulus gradually increases with the increase of the compaction degree.

3.3. Test on CBR. CBR is used to assess the strength indexes of subgrade and pavement materials. In the CBR test, load and penetration reading of plunger were observed at a rate of $1.25 \mathrm{~mm} /$ minute; the load for $2.5 \mathrm{~mm}$ and $5 \mathrm{~mm}$ were 
TABLE 3: The results of CBR tests under different degrees of compaction.

\begin{tabular}{|c|c|c|c|c|c|c|}
\hline $\begin{array}{l}\text { Sample } \\
\text { number }\end{array}$ & $\begin{array}{c}\text { Number of } \\
\text { blows }\end{array}$ & $\begin{array}{l}\text { Dry density } \\
\rho_{d} /\left(\mathrm{g} \cdot \mathrm{cm}^{-3}\right) \\
\end{array}$ & $\begin{array}{c}\text { Compaction degree } \\
K / \% \\
\end{array}$ & $\begin{array}{c}\text { CBR } \\
\% \\
\end{array}$ & $\begin{array}{c}\text { Soaking swelling } \\
\mathrm{Q} / \% \\
\end{array}$ & $\begin{array}{c}\text { Water absorbing } \\
\mathrm{X} / \mathrm{g} \\
\end{array}$ \\
\hline (1) & \multirow{2}{*}{98} & 2.104 & 99.9 & 61.24 & 0.088 & 28 \\
\hline$(2)$ & & 2.102 & 99.7 & 57.14 & 0.074 & 25 \\
\hline (4) & \multirow{2}{*}{50} & 2.060 & 97.7 & 49.71 & 0.108 & 49 \\
\hline (5) & & 2.053 & 97.5 & 48.76 & 0.102 & 48 \\
\hline (7) & \multirow{2}{*}{30} & 2.010 & 95.4 & 35.14 & 0.164 & 108 \\
\hline (8) & & 2.006 & 95.2 & 34.00 & 0.155 & 99 \\
\hline
\end{tabular}

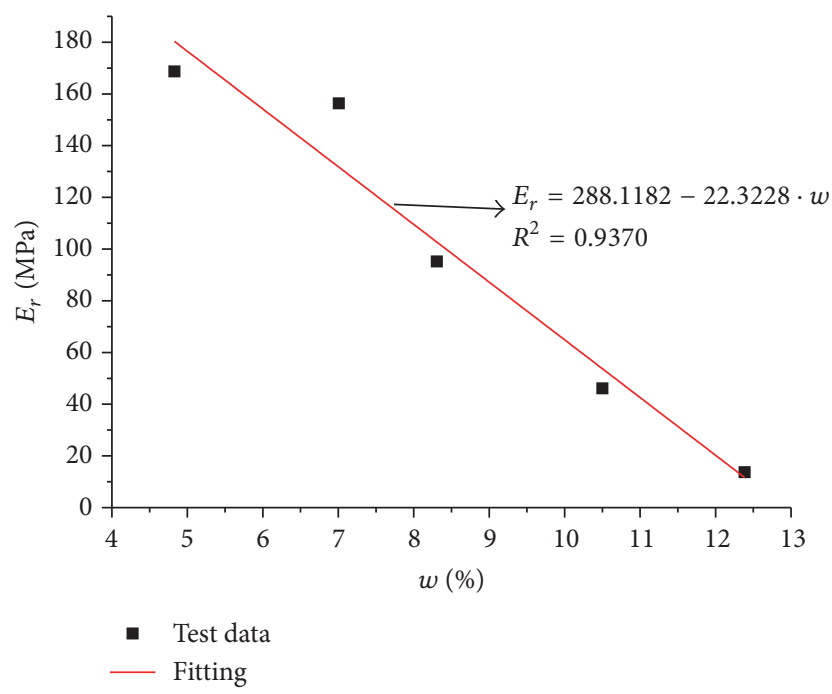

FIGURE 6: Relation between resilient modulus $E_{r}$ and moisture content $\omega$.

observed. CBR value is the comparison between applied piston loads on a soil sample and the standard loads.

Typically, CBR value is calculated by the load for $2.5 \mathrm{~mm}$ as follows:

$$
\mathrm{CBR}=\frac{p}{7000} \times 100,
$$

where $p$ is applied stress, $\mathrm{kPa}$.

At the same time, CBR value is calculated by the load for $5 \mathrm{~mm}$ as follows:

$$
\mathrm{CBR}=\frac{p}{10500} \times 100 .
$$

If the value from (4) is greater than that from (3), the test should be carried out once more. If the result is still like that, CBR value calculated by the load for $5 \mathrm{~mm}$ would be adopted.

The specimens with different degrees of compaction were prepared with each layer having blows of 30, 50, and 98 with the same moisture content $9.0 \%$, to explore the influences of compaction degree $K$ on CBR, the soaking swelling $Q$, and water adsorption $X$, which were evaluated by the Chinese Industrial Standard [18]. The test results are shown in Table 3 and Figures 8-10.

Figure 8 shows the relationship between CBR and compaction degree $(K)$. It can be seen that (1) all the compacted

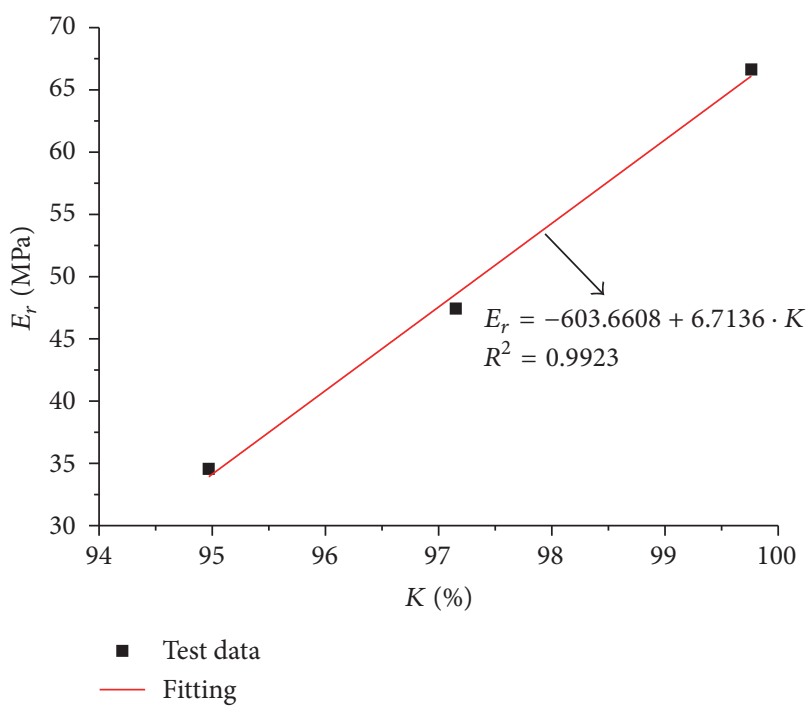

FIGURE 7: Relation between resilient modulus $E_{r}$ and compaction degree $K$.

specimens with different dry densities have higher CBR values; for example, the CBR value of the specimen with $95 \%$ compaction degree can reach up to $30 \%$ or more, which shows that the compacted specimens have a strong ability to resist damage; (2) with the increase of the compaction degree, the CBR value presents a linear increasing trend. According to the national standard [20] of China, the CBR of the fillings for highway should not be lower than $8 \%$ when the $96 \%$ degree of compaction is proposed. The results suggest that the compacted specimens fully meet the requirements of national standard [20].

Figures 9 and 10 give the relationship of the soaking swelling $(Q)$ and the water adsorption $(X)$ with the degree of compaction $(K)$, respectively. It can be seen that the compaction degree has basically the same influence on the soaking swelling and the water adsorption. The higher the compaction degree is, the smaller the soaking swelling and water adsorption become, which show that the water stability is gradually enhanced with the increase of compaction degree. This is mainly due to higher compaction degree leading to a decrease of porosity among the soil particles. In other words, the water storage space of specimens is reduced, characterized by declining of the water absorbing capacity. 


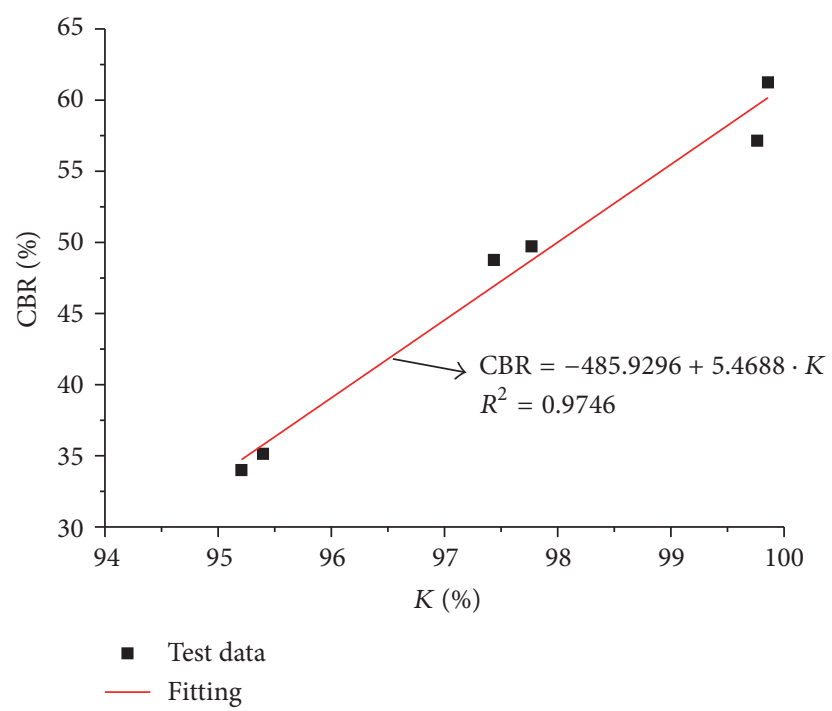

FIgURE 8: Relation between CBR and compaction degree $K$.

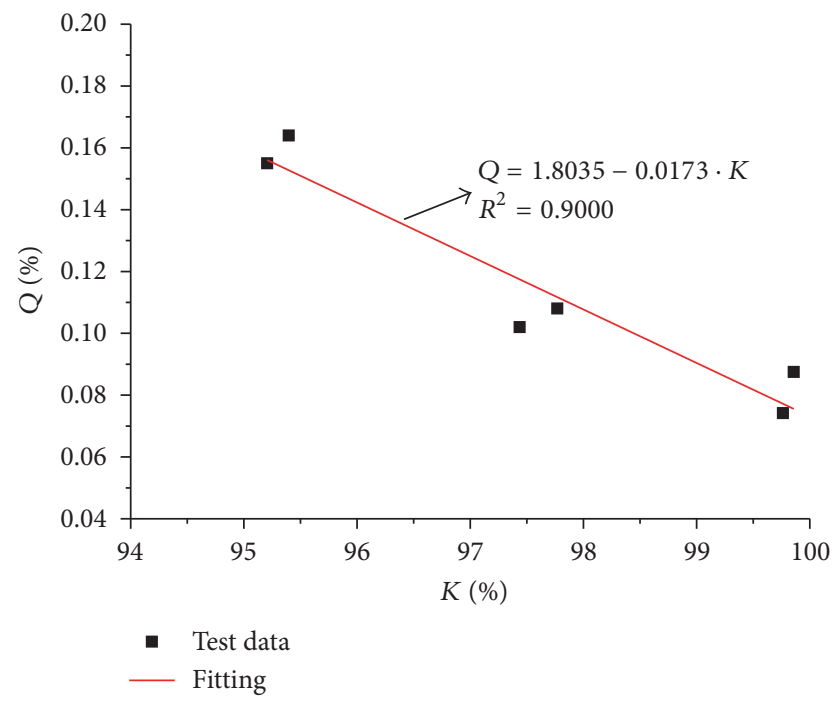

FIGURE 9: Relation between soaking swelling $Q$ and compaction degree $K$.

From the long-term stability of the roadbed, the compaction of red-bed sandstone fillings should be controlled as well as possible. In this condition, the adverse effect of water on the strength of the roadbed can be reduced significantly.

3.4. Test on Permeability. In order to study the relationship between the permeability coefficient $(k)$ and the compaction degree $(K)$, a variable water head method was adopted for the seepage experiment of the saturated specimens with varied compaction degrees $(K=99.6 \%, 96.9 \%, 94.9 \%$, and $96.9 \%)$. The results are shown in Figure 11.

Figure 11 reflects the influences of compaction degree on permeability. It can be seen that (1) the permeability coefficients of the filling decrease linearly with the increase of the compaction degree; with the increasing of the compaction degree, the porosity becomes smaller, and the pore water

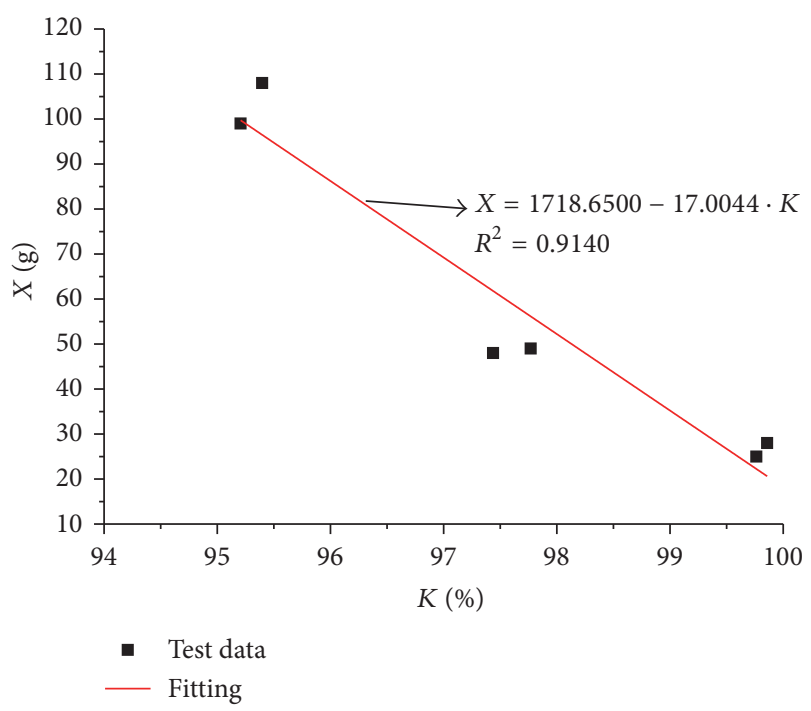

Figure 10: Relation between water absorbing $X$ and compaction degree $K$.

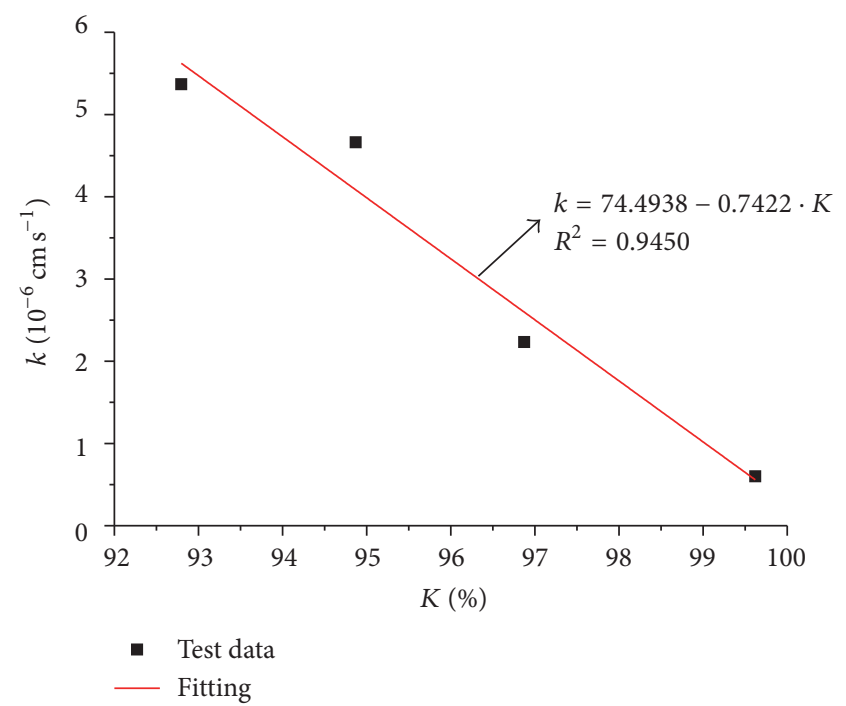

FIGURE 11: Relation between permeability coefficient $k$ and compaction degree $K$.

pressure increases; so, the flowing of free water among soil particles slows down or even stops due to the capillary effect, which leads to the decreasing of the permeability coefficient; (2) with the compaction degree of $92 \%$ to $100 \%$, the permeability coefficients $k$ are less than $1.0 \times 10^{-6} \mathrm{~cm} / \mathrm{s}$, showing a good antipermeability performance and thus proving that the compaction degree has an effective controlling effect on the porosity and permeability coefficients.

\section{Discussion}

The special properties of red-bed soft rocks, such as slaking or softening in water, should be full considered in materials for road construction. Based on the above physical and 
mechanical properties of crushed soft rock matrix, the redbed soft rocks have good engineering properties for subgrade after being crushed and compacted. The red-bed soft rocks mixtures become fine-grained soil during the rolling process. The compaction and other construction technologies can improve the particle grading, which leads to good engineering properties.

Compaction degree is a key factor to ensure that the mechanical properties of the crushed rock mixtures meet the requirements. So, the compaction degree should be selected as the main quality control index for the red-bed roadbed construction in practice.

When the compaction degree of the crushed red-bed rock mixtures is above $90 \%$, the permeability is very small, similar to that of clay. The moisture has great influences on the mechanical properties, and some waterproof measures should be taken on the subgrade slope in the actual highway construction project.

\section{Conclusions}

(1) The red-bed soft rocks in the southern mountains of Anhui Province, China, have complex and diversified lithology and structure. The clay mineral contents are higher with a mud-calcium cementation, minimal strength, and weak weathering resistance.

(2) The moisture has great influences on the resilient modulus of the red-bed crushed soft rock mixtures. The resilient modulus decreases with the increase of moisture content. Therefore, the moisture content of the mixtures should be controlled close to the OWC when rolling to ensure the subgrade resilient modulus meeting the requirements of road construction.

(3) The compaction degree has close relationship with the filling's strength and water stability. With the increase of the compaction degree, the resilient modulus and CBR of the compacted specimens show linear increasing trends, while the soaking swelling, water absorbing capacity, and permeability coefficient present linear decreasing trends.

(4) The laboratory experimental results show that, under certain key control indices such as moisture content or degree compaction, the engineering properties of the crushed red-bed soft rock mixtures can meet the demands of highway construction.

\section{Competing Interests}

The authors declare that they have no competing interests.

\section{Acknowledgments}

The work reported in this paper has received financial support from the National Natural Science Foundation of China (no. 51579063). This support is gratefully acknowledged.

\section{References}

[1] J. A. Franklin and R. Chandra, "The slake-durability test," International Journal of Rock Mechanics and Mining Sciences and, vol. 9, no. 3, pp. 325-328, 1972.

[2] G. Dhakal, T. Yoneda, M. Kato, and K. Kaneko, "Slake durability and mineralogical properties of some pyroclastic and sedimentary rocks," Engineering Geology, vol. 65, no. 1, pp. 31-45, 2002.

[3] M. A. Kanji, "Critical issues in soft rocks," Journal of Rock Mechanics and Geotechnical Engineering, vol. 6, no. 3, pp. 186195, 2014

[4] D. Wu, H. Liu, and G. Wang, "Laboratory experimental study of slaking characteristics of soft rock," Chinese Journal of Rock Mechanics and Engineering, vol. 29, supplement 2, pp. 41734179, 2010 (Chinese).

[5] M. He, "Latest progress of soft rock mechanics and engineering in China," Journal of Rock Mechanics and Geotechnical Engineering, vol. 6, no. 3, pp. 165-179, 2014.

[6] P. Azadan and K. Ahangari, "Evaluation of the new dynamic needle penetrometer in estimating uniaxial compressive strength of weak rocks," Arabian Journal of Geosciences, vol. 7, no. 8, pp. 3205-3216, 2014.

[7] X. Li and Q. Jin, "Compacting deformation engineering characteristics of weathered soft rock mixture in subgrade," Journal of China University of Geosciences, vol. 19, no. 3, pp. 298-306, 2008.

[8] P. Miščević and G. Vlastelica, "Impact of weathering on slope stability in soft rock mass," Journal of Rock Mechanics and Geotechnical Engineering, vol. 6, no. 3, pp. 240-250, 2014.

[9] H. Zhou, C. Zhang, Z. Li, D. Hu, and J. Hou, "Analysis of mechanical behavior of soft rocks and stability control in deep tunnels," Journal of Rock Mechanics and Geotechnical Engineering, vol. 6, no. 3, pp. 219-226, 2014.

[10] H. Cetin, M. Laman, and A. Ertunç, "Settlement and slaking problems in the world's fourth largest rock-fill dam, the Ataturk Dam in Turkey," Engineering Geology, vol. 56, no. 3-4, pp. 225242, 2000.

[11] N. Yoshida and K. Hosokawa, "Compression and shear behavior of mudstone aggregates," Journal of Geotechnical and Geoenvironmental Engineering, vol. 130, no. 5, pp. 519-525, 2004.

[12] M. Aziz, I. Towhata, S. Yamada, M. U. Qureshi, and K. Kawano, "Water-induced granular decomposition and its effects on geotechnical properties of crushed soft rocks," Natural Hazards and Earth System Science, vol. 10, no. 6, pp. 1229-1238, 2010.

[13] M. Rodgers, G. Hayes, and M. G. Healy, "Cyclic loading tests on sandstone and limestone shale aggregates used in unbound forest roads," Construction and Building Materials, vol. 23, no. 6, pp. 2421-2427, 2009.

[14] M. H. Zhao, J. Y. Deng, and W. G. Cao, "Study of the disintegration character of red sandstone and the construction techniques of red sandstone embankment," China Journal of Highway and Transport, vol. 16, no. 7, pp. 1-5, 2003 (Chinese).

[15] H. Peng, "Perspectives on the red beds landforms in humid area of Southern China and some related problems," Geographical Research, vol. 30, no. 10, pp. 1739-1752, 2011 (Chinese).

[16] Y.-C. Guo, Q. Xie, and J.-Q. Wen, "Red beds distribution and engineering geological problem in China," Hydrogeology and Engineering Geology, vol. 6, pp. 67-71, 2007 (Chinese).

[17] X.-S. Mao, L.-G. Zhou, B. Ma, X.-Z. Zheng, and W.-Y. Zhao, "Research on improvement technology of filling subgrade with highly-weathered phyllite," China Journal of Highway and Transport, vol. 25, no. 2, pp. 20-26, 2012 (Chinese). 
[18] The Ministry of Communications of the People's Republic of China, Test Methods of Soil for Highway Engineering (JTG E40-2007), The Ministry of Communications of the People's Republic of China, Beijing, China, 2007 (Chinese).

[19] A. J. Puppala, Estimating Stiffness of Subgrade and Unbound Materials for Pavement Design, NCHRP Synthesis 382, Transportation Research Board, National Research Council, Washington, DC, USA, 2007.

[20] The Ministry of Communications of the People's Republic of China, "Technical specification for construction of highway subgrade," Tech. Rep. JTG F10, 2006 (Chinese). 

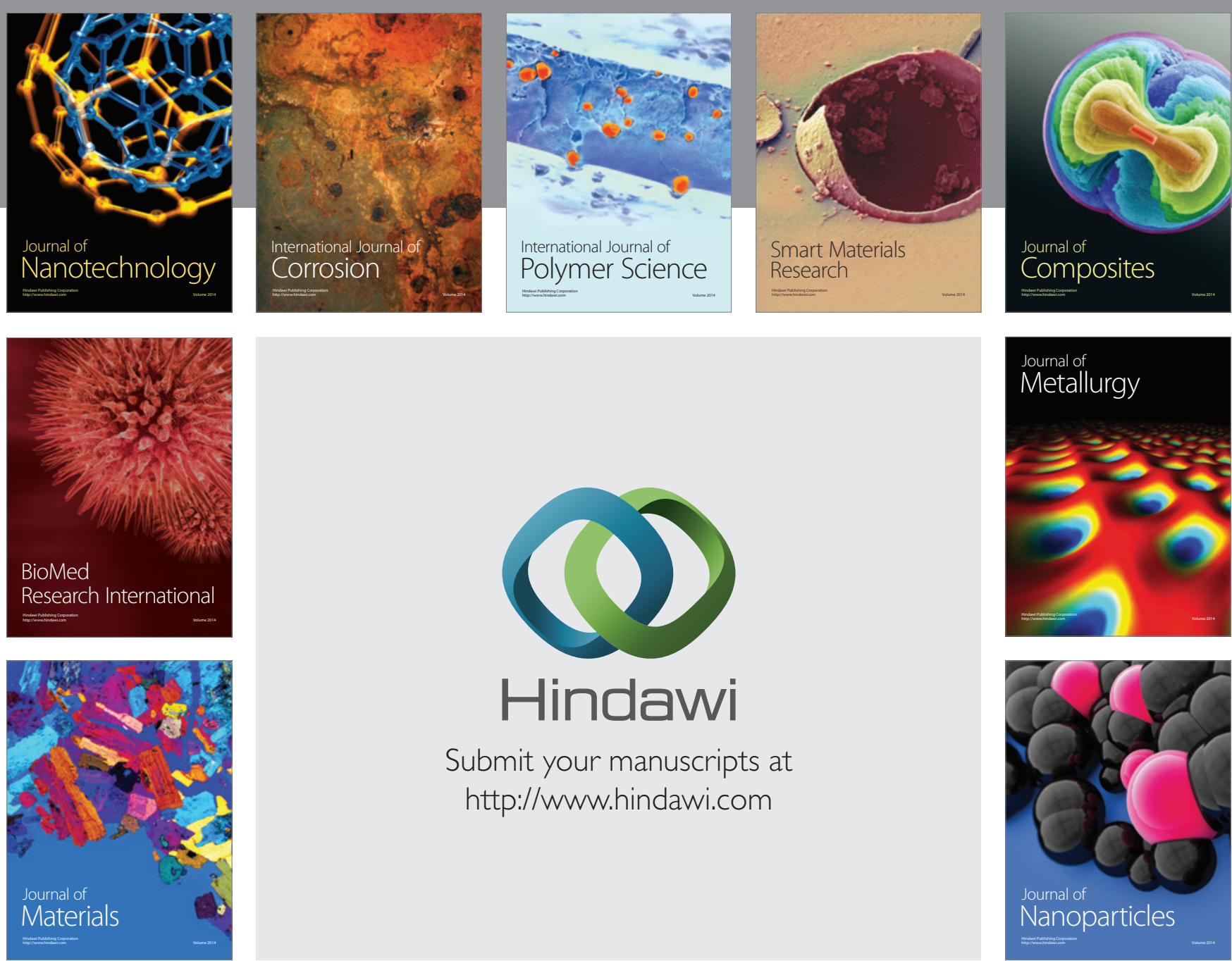

\section{Hindawi}

Submit your manuscripts at

http://www.hindawi.com

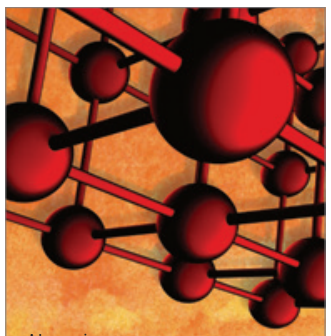

Materials Science and Engineering
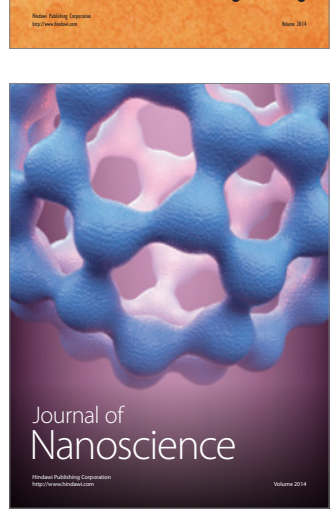
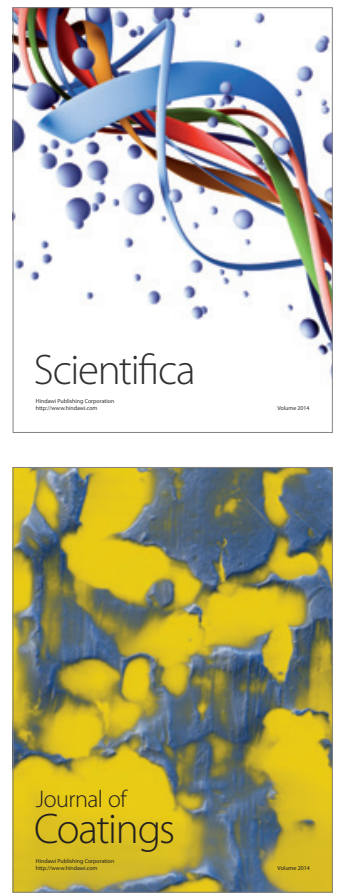
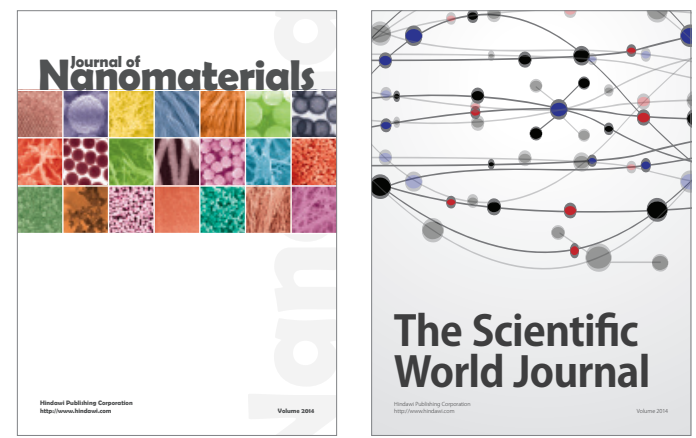

The Scientific World Journal
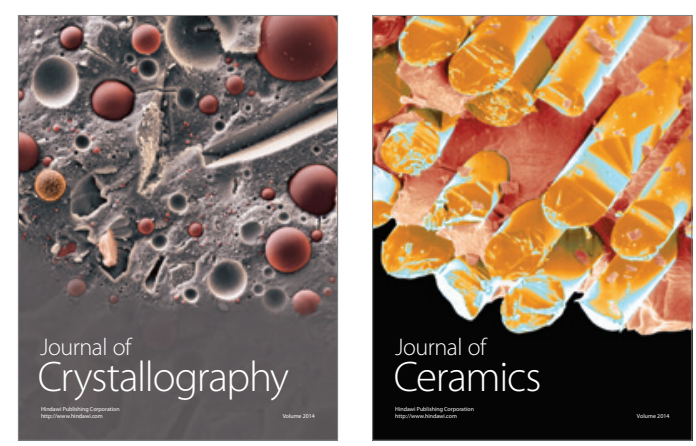
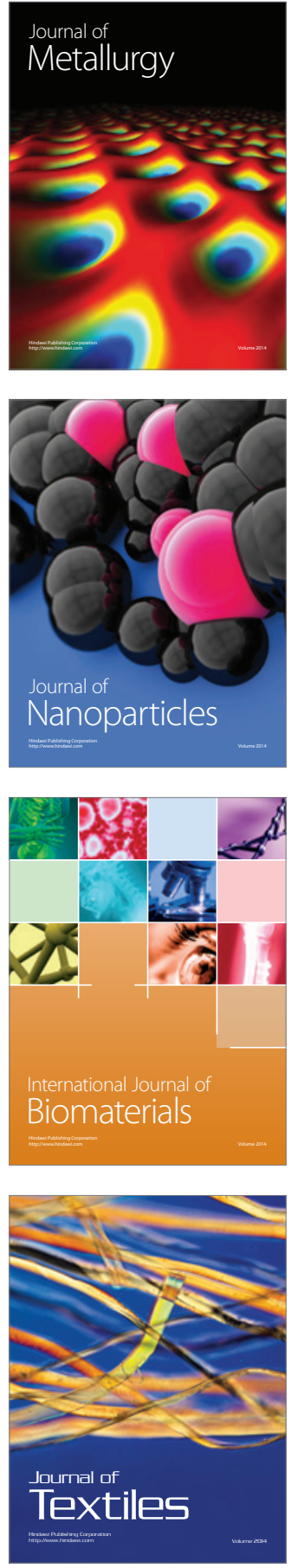